\title{
A rare case of cervical fibroid presenting as retained placenta with postpartum hemorrhage
}

\author{
Meenakshi Chowdhury $^{1}$, Vineeta Gupta ${ }^{1}$, Vidushi Jyala Jain ${ }^{1}$, Aparna Bhardwaj ${ }^{2}$
}

\author{
${ }^{1}$ Department of Obstetrics \& Gynaecology, Shri Guru Ram Rai Institute of Medical \& Health Sciences, Dehradun, \\ Uttarakhand, India \\ ${ }^{2}$ Department of Pathology, Shri Guru Ram Rai Institute of Medical \& Health Sciences, Dehradun, Uttarakhand, India
}

Received: 12 February 2015

Accepted: 01 March 2015

\section{*Correspondence:}

Dr. Meenakshi Chowdhury,

E-mail: minaxitumul@gmail.com

Copyright: (c) the author(s), publisher and licensee Medip Academy. This is an open-access article distributed under the terms of the Creative Commons Attribution Non-Commercial License, which permits unrestricted non-commercial use, distribution, and reproduction in any medium, provided the original work is properly cited.

\begin{abstract}
Fibroids during pregnancy are often asymptomatic but sometimes may lead to various complications and unusual presentations. We are reporting an unusual case of cervical fibroid during pregnancy that presented as retained placenta with postpartum hemorrhage following a full term normal vaginal delivery.
\end{abstract}

Keywords: Degenerated leiomyoma, Vaginal myomectomy, PPH (post-partum hemorrhage), Cervical fibroid

\section{INTRODUCTION}

Fibroid may be seen in $2 \%$ of pregnant women. ${ }^{1}$ Usually these are asymptomatic not causing any problem during pregnancy. But sometimes myoma may give rise to certain complications. Postpartum hemorrhage is one such complication. We are reporting an unusual case of cervical fibroid during pregnancy that presented as retained placenta with postpartum hemorrhage, following a full term normal vaginal delivery elsewhere.

\section{CASE REPORT}

A 34 years old para-2 presented in emergency with complaint of excessive vaginal bleeding following delivery. There was history of full term normal vaginal delivery with episiotomy at a private hospital three hours back. This patient was an un-booked case and there was no record related to antenatal checkups. Moreover, there were no routine investigations as well as obstetric ultrasound with the patient. According to the patient, there was no difficulty in the delivery of the baby but patient was not aware about expulsion of placenta. There was no record related to her delivery. Her previous delivery was 2 years back, which was also an uneventful normal vaginal delivery. On examination, vitals were normal. On per abdominal examination, two globular structures were palpated one above the other. Upper one was moving side by side measuring approximately $4 \mathrm{~cm}$ $\mathrm{x} 4 \mathrm{~cm}$ and was cystic in nature. The other was firm measuring approximately same size $(4 \mathrm{~cm} \times 4 \mathrm{~cm})$ in size with restricted mobility. On local examination, there was an unrepaired right medio-lateral episiotomy. On pervaginum examination, moderate fresh bleeding was present, cord was not palpable, and a soft structure was palpated whose upper pole was continuing with the uterus. An emergency ultrasound was also done which revealed cotyledon like structures in the mass seen in the lower part of vagina, well separated from the empty uterus above the mass. Diagnosis of retained placenta was made and patient shifted to operation theatre for emergency manual removal of placenta under general anesthesia .Intra-operatively manual removal of placenta was tried but complete removal was not possible. Initially, the structure was looking like abnormal placental tissue, but as the procedure progressed it 
revealed more of atrophic structure and pointed towards some abnormal placentation (Figure 1). Surprisingly, after removing a major bulk, the margin of mass was found adherent to anterior cervical lip. Moreover, a diagnosis could not be made out due to the distorted anatomy of dilated cervix. The mass was clamped, cut and ligated nearest to its origin. Initially, retained placenta was our first differential diagnosis; however, as the case was progressed, this led to a diagnostic dilemma. We sent out the specimen for histo-pathological investigation. At the conclusion of surgery, the uterus was well contracted and bleeding was controlled. Uterus and both ovaries with adnexa were preserved. One unit of blood transfused intra-operatively (Hb-6.5 gm\%). Postoperative course was uneventful and she was discharged in satisfactory condition on fifth postnatal day. Serum $\beta$ hCG sent at the time of admission was $12969 \mathrm{MIU} / \mathrm{ml}$ as we were also considering the possibility of a placental tumour. Histo-pathological examination confirmed the big mass as leiomyoma with few degenerative changes (Figure 2). Post-operative follow-up after one month was satisfactory.

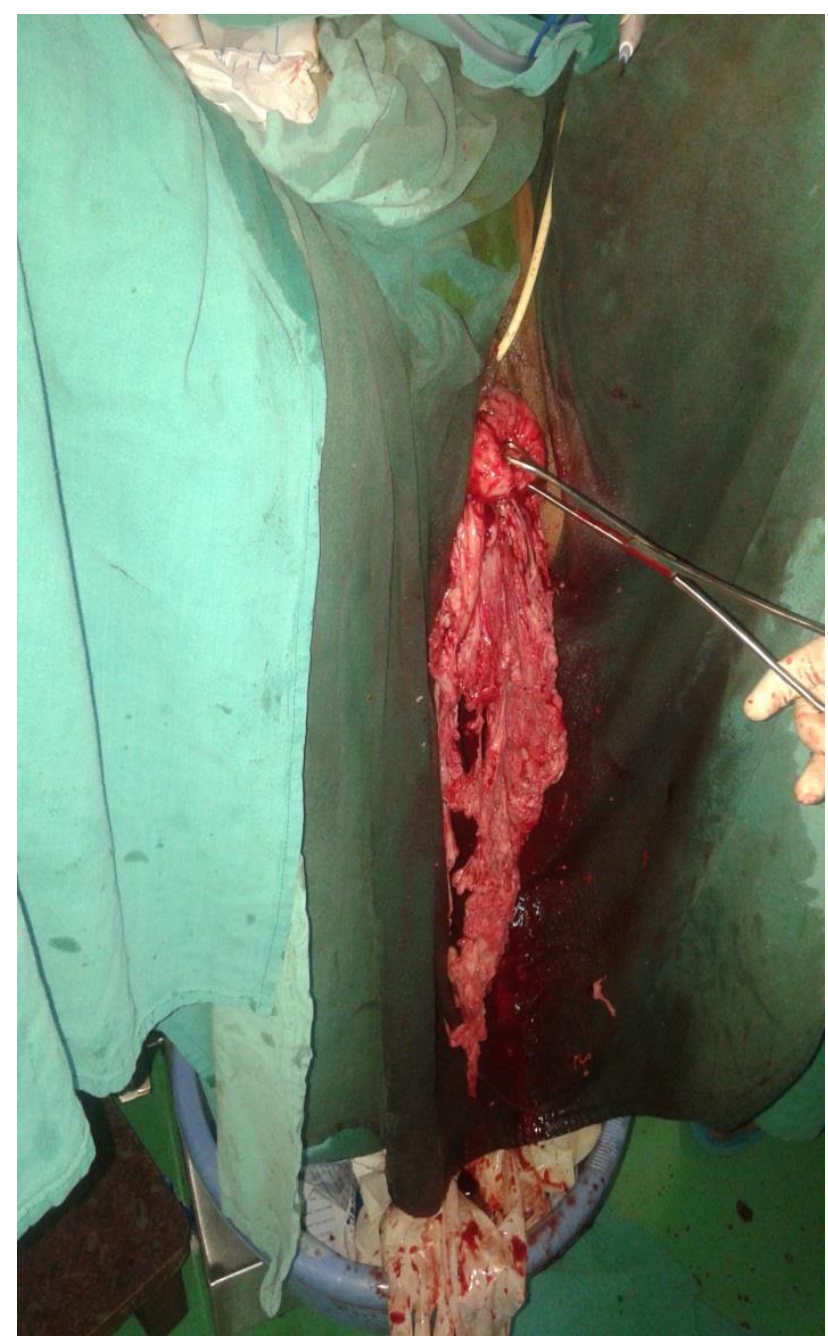

Figure 1: Showing intraoperative removal of mass per vaginally.

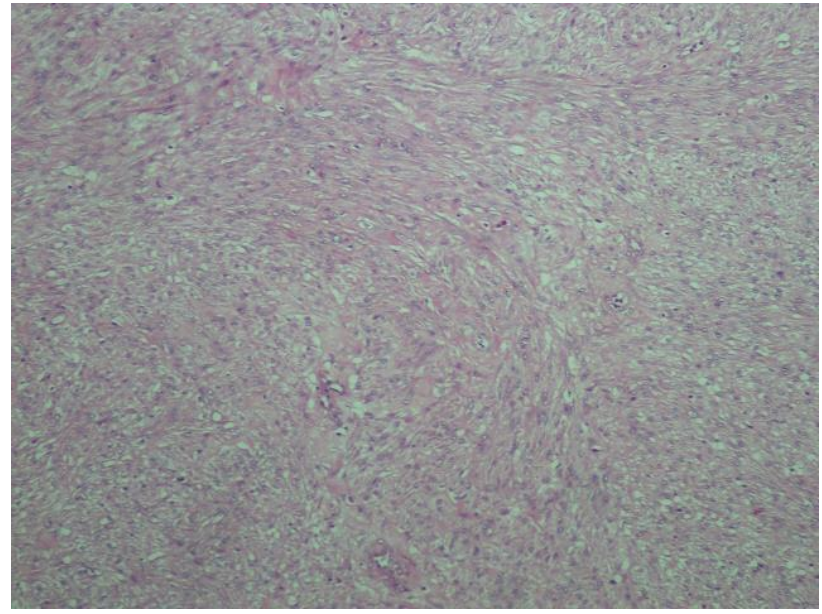

Figure 2: Showing histopathological view of the excised cervical myoma.

\section{DISCUSSION}

Most of the leiomyomas are situated in the body of the uterus, but in approximately $1 \%$ of the cases, they are confined to cervix and usually to the supra-vaginal portion. $^{2}$ A cervical leiomyoma is commonly single and is either interstitial or sub-serous. Rarely it becomes submucous and polypoidal. A cervical fibroid can lead to urinary retention, urinary frequency, constipation, menstrual abnormalities, dyspareunia, and sometimes post coital bleeding but may give unusual presentation. Fibroid during pregnancy usually presents with recurrent abortion, red degeneration causing pain and fever, preterm delivery, abnormal lie and presentation, increased cesarean rate because they may cause obstruction of labour and sometimes need enucleation to facilitate a vaginal delivery .In some cases, even huge cervical myoma may not interfere with normal delivery. Kanti et al. reported a rare case of repeated expulsions of giant cervical fibroid per vagina followed by delivery of near term babies in two consecutive pregnancies, without any postpartum complication. ${ }^{3}$ However fibroid may also cause post-partum hemorrhage in some cases. Adagi et al. reported a case of huge polypoidal uterine myoma causing severe primary post-partum hemorrhage prompting emergency postpartum digital vaginal myomectomy following which bleeding was controlled. ${ }^{4}$ Our case has similar presentation except that initially it looked like a case of retained placenta. In addition to clinical assessment, radiological diagnosis (USG) also revealed placental tissue. Therefore this article highlights a rare example of a case in which clinical, radiological findings could not reveal the exact diagnosis and thefinal diagnosis could be made after histopathological report.

\section{CONCLUSION}

Though large cervical fibroid usually presents with obstruction of labour but degenerated fibroid may allow normal delivery but can cause post-partum hemorrhage and can give appearance of placenta. Better 
multidisciplinary approach and anticipation of differentials may be helpful in the diagnosis and management of such cases. Prompt surgical intervention and transvaginal enucleation of the myoma is the most appropriate management in such case for controlling hemorrhage immediately.

Funding: No funding sources

Conflict of interest: None declared

Ethical approval: Not required

\section{REFERENCES}

1. Cunningham F, Leveno K, Bloom S, Spong CY, Dashe J, Hoffman BL, et al. Fibroid in pregnant women. In: Cunningham F, Leveno $\mathrm{K}$, Bloom S, Spong CY, Dashe J, Hoffman BL, et al., eds. Williams Obstetrics. 24th ed. New York: McGrawHill Education; 2014: 1224.
2. Padubidri VG, Daftary SN. Leiomyomas. In: Padubidri VG, Daftary SN, eds. Shaw's Textbook of Gynaecology. 6th ed. US: Elsevier; 2014: 392.

3. Kanti V, Mishra P, Gupta V, Vishwakarma S, Kumari K, Pandey P. A rare case of repeated expulsions of a giant cervical fibroid per vaginum followed by delivery of near term babies in two consecutive pregnancies. Int $\mathrm{J}$ Reprod Contracept Obstet Gynecol. 2014;3(3):790-2.

4. Adaji SE, Shittu SO, Ageda BR. A huge polypoid uterine myoma causing severe primary postpartum haemorrhage. A report of one case. Niger J Surg Res. 2005;7(1-2):220-1.

DOI: $10.5455 / 2320-1770 . i j r \operatorname{cog} 20150448$

Cite this article as: Chowdhury M, Gupta V, Jain VJ, Bhardwaj A. A rare case of cervical fibroid presenting as retained placenta with postpartum hemorrhage. Int J Reprod Contracept Obstet Gynecol 2015;4:505-7. 